Research Article

\title{
Study of patterns of prescribing antibiotics in geriatric patients admitted to the medical wards in a tertiary care hospital
}

\author{
Ankita Bist*, Gajanan P. Kulkarni, Kashinath M. Gumma
}

Department of Pharmacology, BRIMS, Bidar, Karnataka, India

Received: 22 November 2015

Accepted: 7 January 2016

*Correspondence to:

Dr. Ankita Bist,

Email: ankitabist9@gmail.com

Copyright: (C) the author(s), publisher and licensee Medip Academy. This is an open-access article distributed under the terms of the Creative Commons Attribution Non-Commercial License, which permits unrestricted noncommercial use, distribution, and reproduction in any medium, provided the original work is properly cited.

\begin{abstract}
Background: Evidence indicates high prevalence of inappropriate prescribing of medicines especially in the elderly. This can cause increased incidence of adverse drug reactions, morbidity, mortality and cost of treatment. Also inappropriate use of antibiotics promotes emergence of antimicrobial resistance. This study aims to study the prescribing patterns of antibiotics administered in geriatric patients, disease conditions for which the antibiotics were prescribed and adherence of these antibiotic prescriptions to the $18^{\text {th }}$ WHO essential medicine list.

Methods: A prospective study was undertaken, over duration of 4 months at the government teaching hospital, Bidar Institute of Medical sciences, Bidar. Patients of either sex above 65 years of age admitted to medicine wards due to infections or those who acquired infection due to hospitalization and were on antibiotic treatment / prophylaxis were included. Data collection was done by scrutinizing the inpatient case sheets and investigation reports. Individual data was collected on preformed performa.

Results: Out of the 140 patients $44.2 \%$ patients were admitted for treatment of respiratory tract infections. $17.1 \%$ of the patients received antibiotics prophylactically. Cefotaxime was observed to be the most commonly prescribed antimicrobial agent. It was included in $50 \%$ of antibiotic prescriptions. It was observed that $90 \%$ of antibiotics prescribed were in adherence to the WHO essential drug list.

Conclusions: Polypharmacy is commonly observed practice in geriatric patients. Apart from increasing the cost of treatment it also promotes irrational prescription of drugs. Most of the prescriptions were in adherence with the WHO's Essential Medicine List but antibiotics were mainly prescribed empirically.
\end{abstract}

Keywords: Geriatric, Antibiotics, Prescribing patterns

\section{INTRODUCTION}

Elderly population forms a heterogeneous group. They show inter-individual variability in age related pharmacodynamics and pharmacokinetic changes. They may also have various associated co-morbidities. This increases their chances of receiving several drugs simultaneously. It can further increase the incidence of ADR's, morbidity, mortality and cost of treatment. ${ }^{1}$ A remarkable increase in elderly population has been noticed worldwide. But safe and effective prescribing of medicine still continues to present a major challenge in this age group. ${ }^{2}$
Antibiotics are the most commonly used and misused therapeutic agents. They comprise $30-50 \%$ of the total drug prescriptions. ${ }^{3}$ Many factors contribute to irrational prescribing such as lack of source of information, diagnostic uncertainty or inexperience of the physician. Even promotion of drug by pharmaceutical industry can increase chances of irrational prescribing. ${ }^{4}$ Widespread use of AMA's has led to the emergence of resistance amongst bacterial pathogens. This has fuelled an ever increasing need for development of new drugs. ${ }^{5}$ Evidence shows that more than $70 \%$ of bacteria associated with hospital acquired infections in US have developed resistance to one or more agents previously used to treat them. ${ }^{6}$ 
Antibiotic resistance is increasing at an alarming rate. Conscious efforts are required by all medical practitioners in order to prevent origin of such multidrug resistant organisms which has the capability to push the medical progress back to as that of pre antibiotic era. ${ }^{7}$

In developing countries such as India cost of healthcare is a primary cause of concern. This is increasing due to progressive increase in the development of antimicrobial resistance. ${ }^{8}$ However most of the prescriptions are usually based on prior experience of the physician. They are often empirical in nature there by promoting incidence of antimicrobial resistance. ${ }^{9}$

Awareness of antibiotic resistance has increased worldwide. Drug utilisation studies are powerful exploratory tools. They can be used to identify early signs of irrational drug use and to ascertain the role of drugs in the society. An effective antimicrobial management program if implemented has the potential to improve patient health care. It can also be used to decrease the cost of care being provided. ${ }^{10}$

Our study will provide data that will help us make recommendations to policy makers and provide a feedback to prescribers to ensure quality healthcare in the geriatric population.

\section{METHODS}

\section{Source of data and study design}

This prospective study was undertaken over a period of 4 months. It was conducted in the medical wards of the tertiary care hospital, Bidar Institute of Medical Sciences, Bidar.

\section{Methods of data collection}

Data collection was done by scrutinizing inpatient case sheets. Individual parameters including demographic details, diagnosis, associated co-morbid conditions, treatment given and laboratory investigations were recorded.

Patients included in the study were:

a) All patients of age 65 years or more hospitalized due to infection or those who acquired infection after hospitalization.

b) Those on antibiotic treatment or prophylaxis in medicine wards.

Patients excluded from the study were:

a) Those with insufficient data in medical records,

b) Those that left against medical advice,

c) Patients with Tuberculosis, HIVor HBsAg positive cases and

d) Patients admitted in ICU.

In total 140 patient records were analysed from admission till discharge and results are expressed as mean \pm SD.
The categorical data are presented as percentage. $18^{\text {th }}$ WHO essential medicine list ${ }^{11}$ was referred to check the adherence of antibiotic prescription.

\section{RESULTS}

Total 140 patients were included in the study out of which $84(60 \%)$ were male and rest $56(40 \%)$ were female. Age distribution was observed as shown in Table 1. Various co-morbid conditions such as COPD, hypertension and diabetes mellitus were also found associated as depicted in Table 2.

Disease patterns observed in the patients included maximum patients with respiratory tract infections in $44.2 \%$ (62 patients). It was followed by $25.71 \%$ (36 patients) with GI problems. While $17.14 \%$ (24 patients) suffering from various other diseases such as cardiovascular diseases who were being given antibiotics prophylactically. This is represented in Figure 1.

The prescribing pattern for antimicrobials was observed as monotherapy being given to $60 \%$ patients. 2 antimicrobial agents were given to $27 \%$ patients. Rest $13 \%$ patients received 3 or more antimicrobial agents. This is shown in Figure 2. On an average 6.78 \pm 2.14 drugs/patient were prescribed of which antibiotics comprised $1.48 \pm 0.92$ drugs/patient. Out of the total 208 prescriptions of antibiotics highest prescription was observed for cefotaxime in 104 prescriptions. It was followed by metronidazole with 36 prescriptions. The least commonly prescribed agents were norfloxacin and amikacin which were prescribed only twice as shown in Figure 3.

Amongst total 208 prescriptions of antimicrobial agents 196 drugs were prescribed as injectable forms while 12 prescriptions comprised of oral administration. It was observed that out of the total 208 prescriptions 188 prescriptions $(90 \%)$ were in adherence to $18^{\text {th }}$ WHO essential drug list while rest $10 \%$ were not.

Table 1: Age distribution of the patients.

\begin{tabular}{|llll|}
\hline S.N. & $\begin{array}{l}\text { Age groups } \\
\text { (years) }\end{array}$ & $\begin{array}{l}\text { No. of } \\
\text { patients }\end{array}$ & $\begin{array}{l}\text { \% of } \\
\text { patients }\end{array}$ \\
\hline $\mathbf{1}$ & $65-74$ & 92 & 66 \\
\hline $\mathbf{2}$ & $75-84$ & 42 & 30 \\
\hline $\mathbf{3}$ & 85 and above & 6 & 4 \\
\hline
\end{tabular}

Table 2: Percentage of patients with associated comorbid condition.

\begin{tabular}{|lll|}
\hline S.N. & Associated co-morbid condition & $\%$ of patients \\
\hline $\mathbf{1}$ & COPD & $36 \%$ \\
\hline $\mathbf{2}$ & Hypertension & $44 \%$ \\
\hline $\mathbf{3}$ & Diabetes mellitus & $14 \%$ \\
\hline $\mathbf{4}$ & Both HTN and DM & $8 \%$ \\
\hline
\end{tabular}




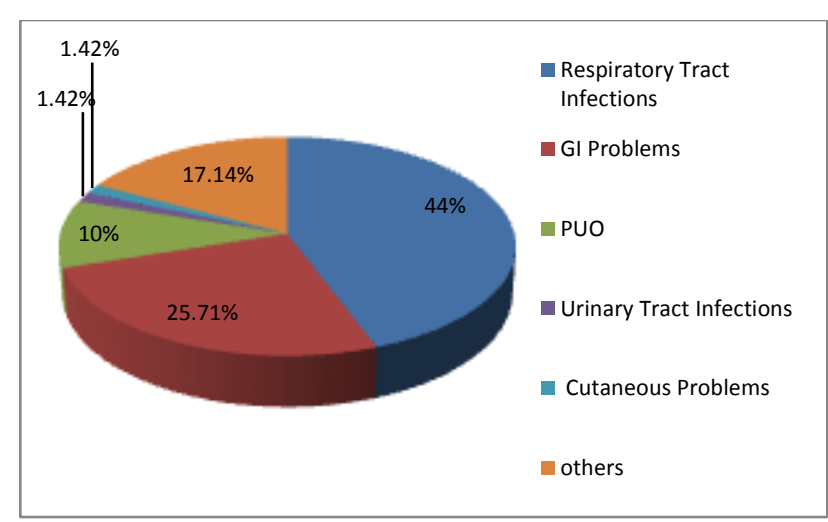

Figure 1: Disease pattern observed in the patients.

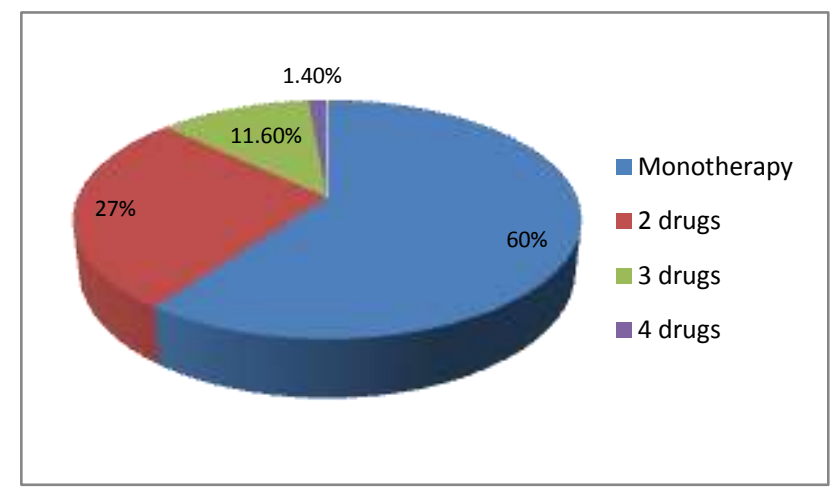

Figure 2: No. of drugs administered.

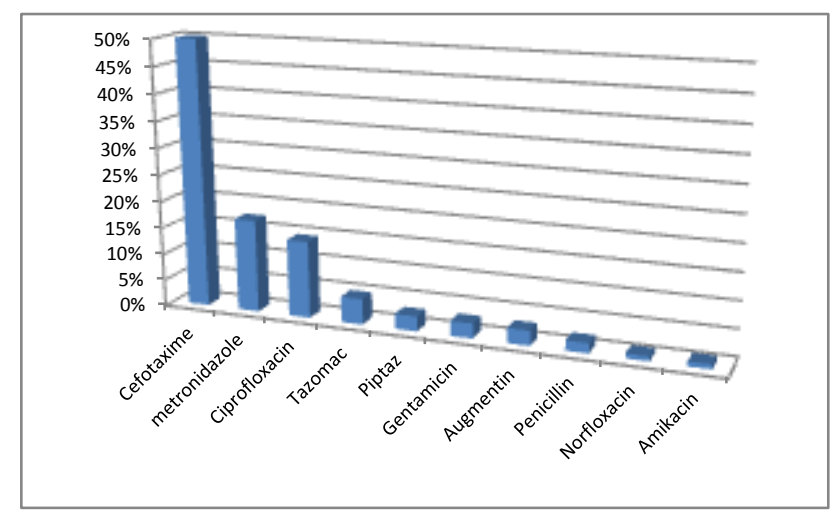

Figure 3: Antibiotic used.

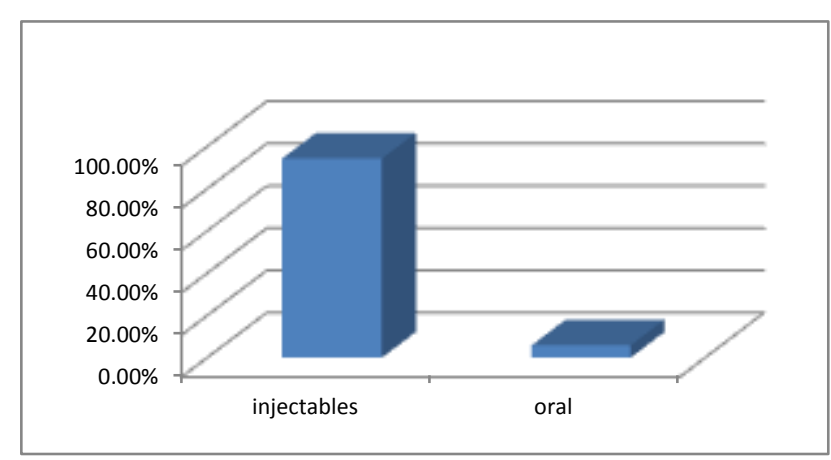

Figure 4: Dosage form.

\section{DISCUSSION}

The present study was done in the patients admitted to the medicine wards in BRIMS, Bidar. Total 140 patients were included in the study. It showed male preponderance with 84 male patients and 56 females as opposed to the study conducted by Binit N. Jhaveri et al which showed preponderance of female patients. ${ }^{12}$ But literature reveals there is no relation of occurrence of infections with gender of the patients. ${ }^{4}$ Age distribution as depicted in Table 1 showed that majority of patients belonged to the age group between 65-74 years.

Most of the patients were reported to have various associated co-morbid conditions mainly COPD, hypertension and DM as shown in Table 2. This resulted in increased incidence of polypharmacy. The average number of drugs per prescription is an important index to complete the prescription audit. Ideally the no. of prescribed drugs should be kept as low as possible. This reduces the risk of drug interactions, adverse drug reactions, and decreases the economic burden as well.

Antibiotics are one of the most frequently prescribed agents amongst hospitalized patients. ${ }^{4}$ In our study an average of $6.78 \pm 2.14$ drugs/prescription were prescribed. Out of which antibiotic prescription comprised of $1.48 \pm 0.92$ drugs/patient. In another study conducted in a tertiary care hospital in northern India total $6.23 \pm 2.73$ drugs were prescribed/patient. Their antibiotics prescription consisted of $2.09 \pm 1.27$ drugs/patient. Out of 140 patients in our study majority were receiving monotherapy with antibiotics while only $1.4 \%$ patients received 4 AMA's as depicted in Figure 2.

Most common indication for prescription of antibiotics was observed to be respiratory tract infection, followed by gastro intestinal problems. Almost $17 \%$ patients suffering from cardiovascular or other diseases were prescribed antibiotics prophylactically on admission. Antibiotics were mainly prescribed empirically. Ideally use of antibiotic after culture and sensitivity testing should be promoted in order to reduce emergence of drug resistance.

The commonest antibiotic prescribed according to our study was cefotaxime as another study conducted by Binit N. Jhaveri et al also indicated cefotaxime to be the commonest prescribed antibiotic. ${ }^{12} 90 \%$ of the prescribed drugs were listed in $18^{\text {th }}$ WHO essential drug lists indicating good adherence to these lists. While 10\% of drugs including amikacin, norfloxacin, fixed drug combinations as tazomac and piptaz, were not mentioned in the lists.

\section{CONCLUSION}

Prescribing practices reflects the health professional's ability to provide best possible management of their patient's conditions. The study of prescribing patterns helps to observe, evaluate, and suggest modifications to 
improve the prescribing habits of the health care providers. This in turn provides more rational and cost effective management to the patients.

\section{ACKNOWLEDGEMENTS}

The authors would like to express their thanks to professors and other staff members of medicine department for permitting us to conduct the study. We would also like to express our gratitude to other staff members of department of pharmacology for their constant support.

Funding: No funding sources

Conflict of interest: None declared

Ethical approval: The study was approved by the Institutional Ethics Committee

\section{REFERENCES}

1. Mclean AJ, Le couteur DG. Aging biology and geriatric clinical pharmacology. Pharmacol Rev. 2004;56(2):163-84.

2. Shah RR. Drug development and use in the elderly: search for the right dose and dosing regimen. British J Clin Pharmacol. 2004;58(5):452-69.

3. Nathiya D, Pandey K, Sharma RK. A study on drug utilization pattern of antimicrobials in outpatient department of medicine at tertiary care hospital. Int J Res Pharm Sci. 2014;4(2):40-5.

4. Preeth M, Shobana J. Study on prescribing patterns of antibiotics used in the management of various infectious diseases in Andhrapradesh. Int Res J Pharm. 2011;2(7):112-5.

5. Bansal D, Mangla S, Undela K, Gudala K, D'Cruz S, Sachdev A et al. Measurement of adult antimicrobial drug use in tertiary care hospital using defined daily dose and days of therapy. Indian J Pharm Sci. 2014;76(3):211-7.
6. Henry F C. General principles of antimicrobial therapy. In: Laurence L. ed. Goodman and Gillman's The pharmacological basis of therapeutics. $11^{\text {th }}$ ed. USA: McGrawHill;2006:1095-09.

7. Badar VA, Kumar S, Navale B. Study of prescribing pattern of antimicrobial agents in medicine intensive care unit of a teaching hospital in central India. JAPI. 2012;60:20-3.

8. Remesh A, Salim S, Gayathri AM, Nair U, Retnavally KG. Antibiotics prescribing pattern in the in-patient departments of a tertiary care hospital. Arch Pharm Pract. 2013;4(2):71-6.

9. Williams A, Mathai AS, Phillips AS. Antibiotic prescription patterns at admission into a tertiary level intensive care unit in Northern India. J Pharm Bioal Sci. 201;3(4):531-6.

10. Ozgenç O, Genç VE, Arı AA, Sibel E, Saçar S, Ozunlu $\mathrm{H}$ et al. Evaluation of the therapeutic use of antibiotics in Aegean region hospitals of Turkey: a multicentric study. Indian $\mathbf{J}$ Med Microbiol. 2011;29(2):124-9.

11. WHO model lists of essential medicines $18^{\text {th }}$ ed. Geneva: World Health Organization, 2013. Available at: http://www.who.int/ medicines/publications/ essentialmedicines/en/ index.html. Accessed 19 Jan 2015.

12. Jhaveri BN, Patel TK, Barvaliya MJ, Tripathi CB. Drug utilization pattern and pharmacoeconomic analysis in geriatric medical in- patients of a tertiary care hospital of India. J Pharmacol Pharmacother. 2014;5(1):15-20.

Cite this article as: Bist A, Kulkarni GP, Gumma KM. Study of patterns of prescribing antibiotics in geriatric patients admitted to the medical wards in a tertiary care hospital. Int J Basic Clin Pharmacol 2016;5:155-8. 